


\section{About IJMA [last updated October, $\left.1^{\text {st }}, 2021\right]$}

$\checkmark$ International Journal of Medical Arts is the Official Journal of the Damietta Faculty of Medicine, AlAzhar University, Egypt

$\checkmark$ It is an International, Open Access, Double-blind, Peer-reviewed Journal

$\checkmark$ Published four times a year

$\checkmark$ The First Issue was published in July 2019

$\checkmark$ Published under the following license: Creative Commons Attribution-ShareAlike 4.0 International Public License (CC BY-SA 4.0). It had updated from the Creative Commons license [CC BY] in volume 2, Issue 4, October 2020 About IJMA

$\checkmark$ The Egyptian Knowledge Bank hosts the web site of IJMA

$\checkmark$ The Egyptian Knowledge Bank supports IJMA

$\checkmark$ IJMA follows the regulations of the International Committee of Medical Journal Editors

$\checkmark$ IJMA is indexed in the "Directory of Open Access Journals" [15 January 2021].

$\checkmark$ IJMA is indexed in J-Gate [29-6-2021]

$\checkmark$ IJMA is a member of the International Society of Managing and Technical Editors

$\checkmark$ Listed in "Index Copernicus", "Publons", "Academic resource index [ResearchBib]" "Electronics journal library", "Eurasian Scientific Journal Index", "WorldCat" Superstar Journal Database, and "Citefactor"

$\checkmark$ IJMA introduced to the search engine [BASE] through DOAJ

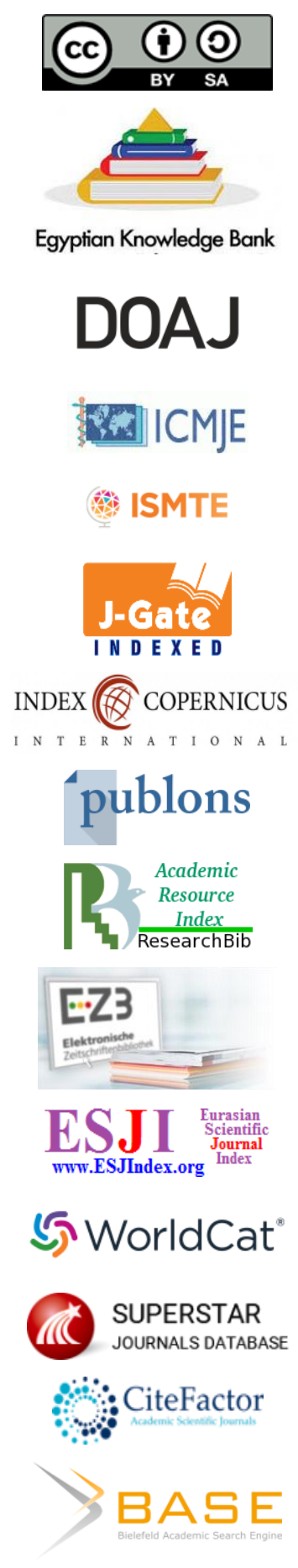




Available online at Journal Website
https://ijma.journals.ekb.eg/
Main subject [Public Health]

Original Article

\title{
Subjective Evaluation of Health Care Services Provided at Outpatient Clinics of Different Levels of Health Care in Cairo
}

\author{
Emad Eldin M. Salama [1], Mohamed Elhady Imam [1], Morsy Ahmed Ammar [1], Tahseen Samir Mohamed [1]
}

${ }^{1}$ Department of Public Health and Community Medicine, Faculty of Medicine [for boys], Al-Azhar University, Cairo, Egypt

Corresponding author: Emad Eldin M. Salama

Email: emadheba63@gmail.com

Submission date: September 26, 2021; Acceptance date: November 5, 2021

DOI: $10.21608 /$ IJMA.2021.98040.1373

DOAJ

\section{ABSTRACT}

Background: Assessment of client's satisfaction about healthcare services is an important tool for improvement of provided healthcare services as it enables the administrators of healthcare facilities to identify areas of least satisfaction from client's point of view that can helps to make services more effective and efficient.

Aim of the work: To assess and compare the degree of patient satisfaction at different levels of health care in Cairo, Egypt.

Methods: An analytical cross-sectional study was carried out. The study included 1131 clients to assess their satisfaction about the received healthcare services after completing their visits and before discharge from the facility. Data was collected through patient interview questionnaire which asked about ten domains of patient satisfaction.

Results: Of studied participants, $47.7 \%$ were in a state of acceptance about overall received medical services while $40.1 \%$ were not satisfied. $4.7 \%$ were not satisfied at all, $7.4 \%$ were satisfied and only $1 \%$ was very satisfied about overall healthcare services at outpatient clinics in the study sites. The mean satisfaction score was statistically significant higher among clients attending primary level regarding accessibility, reception service, environment of unit, doctor performance, nurse performance, pharmacy services, patient rights and overall satisfaction. On the other hand mean satisfaction score was statistically significant higher among clients attending tertiary level in comparison to secondary and primary level regarding effectiveness of health care.

Conclusion: The majority of participants in our study were not satisfied with overall services in the study sites. Nurse performance, patient rights and continuity of services were the domains of least satisfaction.

Keywords: Patient satisfaction; Quality of healthcare; Levels of healthcare.

This is an open-access article registered under the Creative Commons, ShareAlike 4.0 International license [CC BY-SA 4.0] [https://creativecommons.org/licenses/by-sa/4.0/legalcode. 


\section{INTRODUCTION}

Quality is a compulsory requirement for health care services, positioning client's satisfaction as an important element within that definition. Patient satisfaction is a major domain of quality and care and considered an objective to be reached. Satisfaction assessment is an instrument for planning and administration, in addition to playing an important role in the communication between service provider and the user, since satisfaction is considered a judgment of the quality of provided care. Quality evaluation through measurement of users' satisfaction is part of the hospitals accrediting process, which is under implementation within the health services ${ }^{[1]}$.

Findings in the developed countries about quality of healthcare services have influenced the developing countries to assess the quality of their healthcare delivery systems. Outcomes have received special prominence as a measure of quality healthcare. Quality assessment studies over the past years usually measure one of three types of outcomes thus patient's satisfaction, costs, and medical outcomes [2],

Patient's satisfaction has gained a great importance nowadays specially in developing countries. It is both a quality component and service quality indicator. Patient satisfaction has been emphasized as the latest trend in most studies manipulating healthcare delivery assessment. It has been realized, that in order to achieve a good competitive advantage in the field of healthcare, the perception of patients for quality need to be deeply evaluated [3].

Patients' perceptions with received health care services are important in bridging the gap between the actual health care provided and the care that should have been provided. Therefore, it is important to analyze the patients' perceptions of satisfaction with the provided health care services. Patients' satisfaction with health care services is determined by patients expectations regarding the healthcare they are about to receive and their perceptions of past healthcare. So, assessment of patients' satisfaction level is now one of WHO indicators to improve the quality of provided healthcare services [4]. Patient satisfaction is an attitude towards the overall experience of received health care service. Satisfaction comprises both emotional and cognitive facets and relates to previous expectations and experiences ${ }^{[5]}$.

The Ministry of Health $[\mathrm{MOH}]$ in Egypt has been concerned with quality of health care services over the past years, which has a strong effect on patient satisfaction, but the improvements in the quality of care has been slow, because quality improvement actions have received inadequate priority. However, there have been many researches in quality of healthcare service, which has patient satisfaction as an indicator of quality assurance in the Egyptian health care facilities. The results of these researches mentioned that Poor quality of healthcare and low level of client satisfaction resulted in loss of patients' lives, revenue, material resources, time, staff, trust and respect. All of which contribute to lowered effectiveness and efficiency in the Egyptian healthcare system [ ${ }^{[6]}$.

In this research a comparative approach with a focus on institutional facilities [University hospital, general hospital and PHC center] in Egypt is used. The novelty of our study is to assess patient's satisfaction within the different levels of healthcare in Egypt.

This study also has answered a frequently asked question; why patients in Egypt attending tertiary hospitals surpassing the primary healthcare center? And the study revealed that the participants found tertiary hospitals more effective than primary health care centres.

\section{AIM OF THE WORK}

Identification of areas of least satisfaction in healthcare services will enable the healthcare administrators to reconsider the introduced services and this will be reflected on patient compliance to preventive and curative measures which described to improve their illness.

\section{PATIENTS AND METHODS}

\section{Study setting, design and participants}

In our study, participants were included from outpatient clinics [Gynecology, Internal medicine and pediatrics clinics] of three health care facilities representing the three health care levels in Cairo governorate:

- The urban primary health care centre of Alhy Alsades, Madint Nasr representing the primary level of health care.

- Dar Al-Salam general hospital representing the secondary health care level.

- Al-Hussein university hospital representing the tertiary health care level.

Inclusion criteria included Clients attending the previous mentioned clinics after visit and before leaving the health care facility.

Exclusion criteria included [Clients attending pediatrics clinic for immunization services, unwilling to participate in the study, the mental conditions makes it impossible to perform interview...etc.] 


\section{Sampling}

Sample Technique: Type of sample is a purposive sample technique to choose the study sites.

- Al-Hussein university hospital was chosen to represent the tertiary health care level as it is Al-Azhar university hospital and this will facilitate the administrative approvals.

- Dar Al-salam general hospital was chosen as the researcher can gain administrative approval from hospital director.

- PHC Centre of Alhay Alsades, Madint Naser was chosen due to presence of administrative coordination between the community department of AL-Azhar faculty of medicine in Cairo and the PHC center.

A systematic random sampling methodology was used on participants. In each healthcare facility we selected a client randomly [1, 4, 7, and 10...etc.]. All attendants who agree with the inclusion requirements were included before the target sample size is met. The sample size was distributed similarly to the three healthcare facilities.

Sample size: The average attendance at outpatient clinics in Al-Hussein university hospital was taken to represent the population size, which were 24039 cases during 2018. The total calculated sample size was 378 case, using Epi info statistical program at $95 \% \mathrm{Cl}$ and $5 \%$ margin of error. We have taken 378 cases from Al Hussein university hospital as follow; $30 \%$ from GYN clinic, $32 \%$ from internal medicine clinic and 38\% from pediatric clinic. We have taken 378 client from Dar el- Salam general hospital were taken as follow; $31 \%$ from GYN clinic, $25 \%$ from internal medicine clinic and $44 \%$ from pediatrics clinic. From the PHC center we have taken 378 cases as follow; $27 \%$ from GYN clinic, $37.6 \%$ from internal medicine clinic and $35.4 \%$ from pediatrics clinic.

\section{Study variables}

- Dependent variable: Patient satisfaction.

- Independent variables: Attendance, patient complaint and Socio-demographic criteria including age, sex, residence, occupation, education level, income and crowding index.

\section{Survey tools of data collection}

Data were collected by using a pre tested, coded, researcher administered, modified questionnaire which has been finalized after reviewing literature review. This questionnaire has been tested by pilot study and was revised by the supervisors. This tool consisted of two parts:

\section{The first part}

It is intended to collect socio-demographic data related to the study subjects; gender, age, residence, education, occupation, income, family number, room number, in addition to complaint, number of the previous visits to clinics.

\section{The second part}

It is intended to assess patient satisfaction and included nine domains in addition to overall satisfaction [tenth domain] as follow:

- First domain: Accessibility of health care services and assessed by ten items.

- Second domain: Reception services and assessed by three items.

- Third domain: Environment of unit and assessed by fourteen items.

- Fourth domain: Doctor performance and assessed by fifteen items.

- Fifth domain: Nurse performance which tackled with three items.

- Sixth domain: Pharmacy services which assessed by four items.

- Seventh domain: Effectiveness of received health care service that had been assessed by three items.

- Eighth domain: Continuity of health care service and assessed by three questions.

- Ninth domain: Patient rights and assessed by two items.

- Tenth domain: Overall satisfaction and assessed by one question.

Responses were measured on a five points rating scale ranged from unsatisfied at all, unsatisfied, accepted, satisfied, and strongly satisfied.

\section{Scoring system}

Responses of patients to the questions were evaluated on a five-point Likert scale, including unsatisfied at all [1score], unsatisfied [2 scores], accepted [3 scores], satisfied [4 scores] and very satisfied [5 score]. 
The level of patient satisfaction with the whole domain was evaluated as follows:

- The total score less than $50 \%$ is classified as [unsatisfied].

- The total score $\geq 50 \%$ is classified as [satisfied].

\section{Ethical approval}

It was obtained from Institutional Review Board at Faculty of Medicine for boys, Al-Azhar University, Cairo. An informed consent from anonymous participants was added as an initial page of the questionnaire before their interview started with emphasis on full voluntary participation and withdrawal at any time without justification.

\section{Statistical analysis}

It was done using the statistical package for the social sciences [SPSS, version 23; SPSS Inc., Chicago, Illinois, USA] [using an IBM personal computer]. Percentage, Frequency, the mean and the standard deviation were used as a descriptive statistics. For groups comparisons, chisquare and t-tests were used for qualitative and quantitative variables respectively. ANOVA with post hoc LSD was used for comparison between more than two quantitative groups via Kolmogorov- Smirnov test [K-S test] and Levene's test for variance equality.

\section{RESULTS}

\section{Socio-demographic characteristics of study participants and healthcare levels}

The study included 1131 participants, $77.6 \%$ of them were female. As regards age groups, the majority [56.3\%] of the studied samples was in age group from 20 to 40 years and the mean age of all clients was $33.9 \pm 15.6$ year. As regards residence, the percentage of clients were living in urban areas was $47.57 \%$ compared to $52.43 \%$ were living in rural and slum areas. As regard educational level, the majority of participants were having university education $61.5 \%$ while the minorities have had a basic education $7.5 \%$ and $7.3 \%$ for illiterate. As regards occupation, the participants not working at time of the study representing $66.8 \%$ compared to having unskilled jobs $11.6 \%$, skilled jobs $13.8 \%$ and professional jobs $1.3 \%$. As regards income most of participants reported income as not enough $54.1 \%$ compared to $6.1 \%$ who reported it as enough and more and $39.8 \%$ who reported it as hardly enough [Table 1 ].
Table [2] showed that there was statistically significant increased level of healthcare [tertiary level] when age were between 20 to 40 years old. There was statistically significant increase in level of health care [secondary and tertiary level] when residence was rural and slum while there was statistically significant decrease in health care level [primary level] when residence was urban. As regards gender, level of education, occupation and income, there was no statistically significant difference between groups in relation to these items.

Figure [1] shows that percentage of clients of acute complaint at tertiary hospital clinics [67.70\%] is more than it at secondary [67.20\%] and primary [39.90\%] health care facilities.

\section{Satisfaction score of participants in all domains of satisfaction}

Figure [2] shows that $47.7 \%$ of studied participants were in a state of acceptance about overall received medical services while $40.1 \%$ were not satisfied. $4.7 \%$ were not satisfied at all, $7.4 \%$ were satisfied and only $1 \%$ was very satisfied about overall healthcare services at outpatient clinics in the study sites.

Table [3] shows that the accessibility and effectiveness of health care services scored highest satisfaction percent $75.2 \%$ and $66.8 \%$ in order. The domains showing least satisfaction percent are in order; nurse performance $0.0 \%$, patient rights $4.9 \%$ and environment of the unit $7.8 \%$.

Table [4] shows that mean satisfaction score was statistically significant higher among clients attending primary level regarding accessibility, reception service, environment of unit, doctor performance, nurse performance, pharmacy services, patient rights and overall satisfaction. On the other hand mean satisfaction score was statistically significant higher among clients attending tertiary level in comparison to secondary and primary level regarding effectiveness of health care.

Post Hoc test [Turkey's test] shows that no statistically significant difference between mean satisfaction score of clients attending primary and tertiary level regarding nurse performance $[P 2=0.171]$. Concerning effectiveness of health care services and patient rights, Turkey's test shows no significant statistically difference between clients at secondary and tertiary levels $[P 3=0.130],[P 3=0.548]$. 
Table [1]: Socio demographic characteristics of the studied population

\begin{tabular}{|c|c|c|c|}
\hline & & $N[=1131]$ & $\%$ \\
\hline Gender & $\begin{array}{l}\text { Male } \\
\text { Female }\end{array}$ & $\begin{array}{l}253 \\
878\end{array}$ & $\begin{array}{l}22.4 \\
77.6\end{array}$ \\
\hline \multirow[t]{6}{*}{ Age group } & $<20$ & 159 & 14.1 \\
\hline & $20-$ & 637 & 56.3 \\
\hline & $40-$ & 229 & 20.2 \\
\hline & $60+$ & 106 & 9.4 \\
\hline & Range & \multirow{2}{*}{\multicolumn{2}{|c|}{$\begin{array}{c}19-68 \\
33.978 \pm 15.688\end{array}$}} \\
\hline & Mean $\pm S D$ & & \\
\hline \multirow[t]{2}{*}{ Residency } & Urban & 538 & $47.57 \%$ \\
\hline & Rural and slum & 593 & $52.43 \%$ \\
\hline \multirow[t]{5}{*}{ Levels of education } & Illiterate & 82 & 7.3 \\
\hline & Read and write & 120 & 10.6 \\
\hline & Basic education & 85 & 7.5 \\
\hline & Secondary & 148 & 13.1 \\
\hline & University & 696 & 61.5 \\
\hline \multirow[t]{5}{*}{ Occupation } & Not working & 755 & 66.8 \\
\hline & Un skilled job & 131 & 11.6 \\
\hline & Skilled job & 156 & 13.8 \\
\hline & Office work & 74 & 6.5 \\
\hline & Professional work & 15 & 1.3 \\
\hline \multirow[t]{3}{*}{ Income } & Not enough & 612 & 54.1 \\
\hline & Hardly enough & 450 & 39.8 \\
\hline & Enough and more & 69 & 6.1 \\
\hline \multirow[t]{2}{*}{ Crowding Index } & $>1$ & 935 & $82.67 \%$ \\
\hline & $\leq 1$ & 196 & $17.33 \%$ \\
\hline
\end{tabular}

Table [2]: Socio demographic characteristics and health care levels

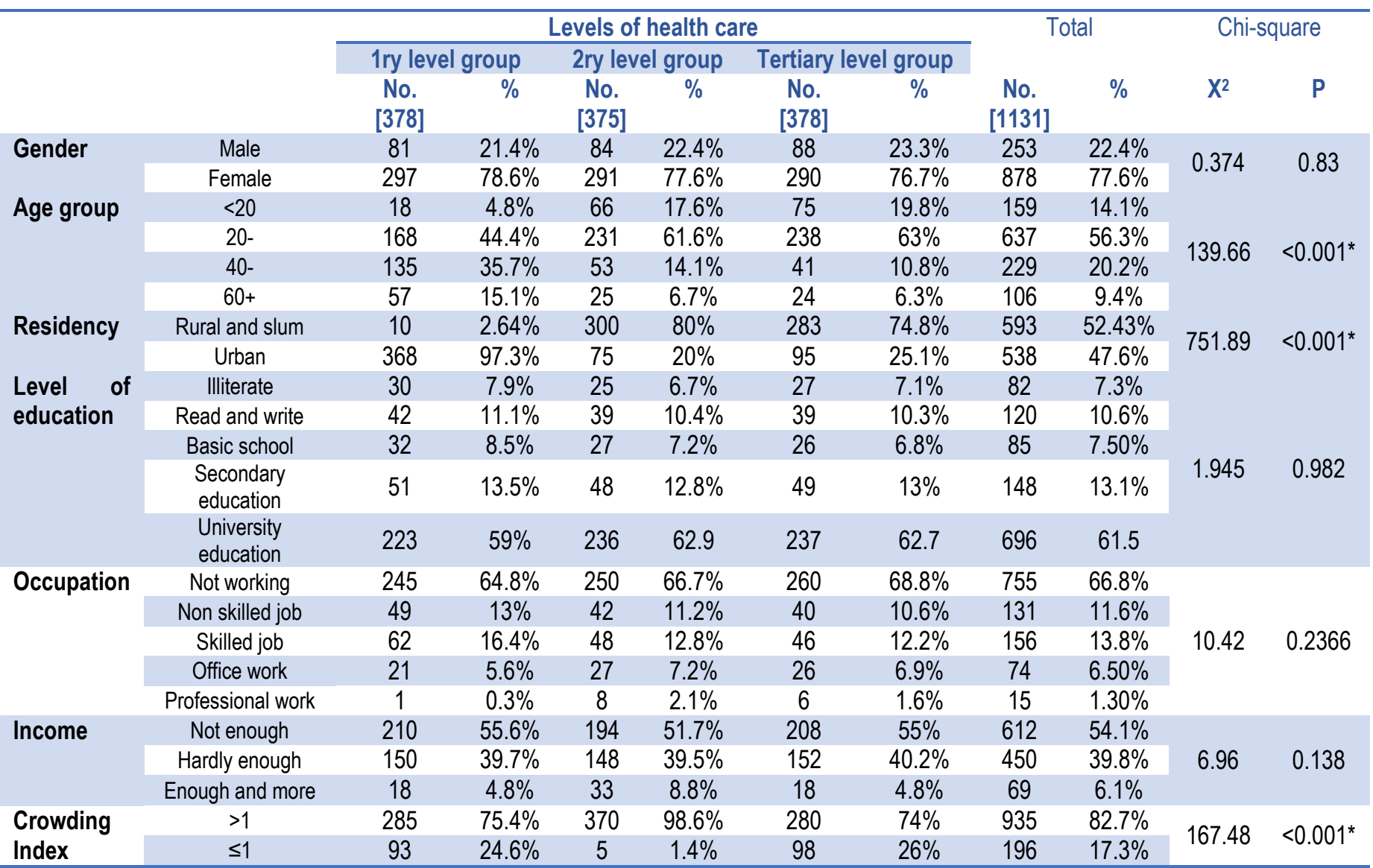


Table [3]: Level of satisfaction of all studied population with different satisfaction domains

\begin{tabular}{lccccc}
\multicolumn{1}{c}{ Domains of satisfaction } & \multicolumn{2}{c}{ Sot satisfied } & \multicolumn{2}{c}{ Satisfied } & Mean score \pm \\
& No. & $\%$ & No. & $\%$ & SD \\
Accessibility of health care service & 281 & $24.8 \%$ & 850 & $75.2 \%$ & $2.86 \pm .55$ \\
Reception Service & 665 & $58.8 \%$ & 466 & $41.2 \%$ & $2.41 \pm .87$ \\
Environment of unit & 1043 & $92.2 \%$ & 88 & $7.8 \%$ & $2.06 \pm .36$ \\
Doctor Performance & 739 & $65.3 \%$ & 392 & $34.7 \%$ & $2.41 \pm .34$ \\
Nurse Performance & 1131 & $100.0 \%$ & 0 & $0.0 \%$ & $1.27 \pm .43$ \\
Pharmacy Service & 862 & $76.2 \%$ & 269 & $23.8 \%$ & $1.60 \pm .70$ \\
Effectiveness of healthcare services & 376 & $33.2 \%$ & 755 & $66.8 \%$ & $2.64 \pm .80$ \\
Patient rights & 1076 & $95.1 \%$ & 55 & $4.9 \%$ & $1.53 \pm .45$ \\
Overall satisfaction & 903 & $79.8 \%$ & 228 & $20.2 \%$ & $2.19 \pm .31$ \\
\hline
\end{tabular}

Table [4]: Mean satisfaction score in the studied groups in relation to domains of satisfaction

\begin{tabular}{|c|c|c|c|c|c|c|c|c|}
\hline \multirow[t]{2}{*}{ Domains of satisfaction } & 1ry level & 2ry level & Tertiary & \multicolumn{2}{|c|}{ ANOVA } & \multicolumn{3}{|c|}{ Tukey's test } \\
\hline & Mean \pm SD & Mean \pm SD & Mean \pm SD & $F$ & $\begin{array}{l}\text { P. } \\
\text { value }\end{array}$ & P1 & P2 & P3 \\
\hline $\begin{array}{l}\text { Accessibility of health care } \\
\text { service }\end{array}$ & $3.23 \pm 0.34$ & $2.79 \pm 0.52$ & $2.56 \pm 0.53$ & 189.69 & 0.000 & 0.000 & 0.000 & 0.000 \\
\hline Reception Service & $3.41 \pm 0.34$ & $1.76 \pm 0.31$ & $2.04 \pm 0.71$ & 1195.82 & 0.000 & 0.000 & 0.000 & 0.000 \\
\hline Environment of unit & $2.33 \pm 0.15$ & $1.86 \pm 0.29$ & $1.96 \pm 0.38$ & 264.88 & 0.000 & 0.000 & 0.000 & 0.000 \\
\hline Doctor Performance & $2.54 \pm 0.41$ & $2.28 \pm 0.29$ & $2.39 \pm 0.21$ & 63.26 & 0.000 & 0.000 & 0.000 & 0.000 \\
\hline Nurse Performance & $1.77 \pm 0.39$ & $1.00 \pm 0.00$ & $1.03 \pm 0.14$ & 1225.34 & 0.000 & 0.000 & 0.171 & 0.000 \\
\hline Pharmacy Service & $2.51 \pm 0.22$ & $1.00 \pm 0.00$ & $1.26 \pm 0.31$ & 4985.37 & 0.000 & 0.000 & 0.000 & 0.000 \\
\hline Effectiveness of healthcare & $2.80 \pm 0.53$ & $2.18 \pm 0.95$ & $2.91 \pm 0.65$ & 108.35 & 0.000 & 0.000 & 0.000 & 0.130 \\
\hline Patient rights & $1.68 \pm 0.38$ & $1.24 \pm 0.43$ & $1.65 \pm 0.38$ & 142.04 & 0.000 & 0.000 & 0.000 & 0.548 \\
\hline Overall satisfaction & $2.55 \pm 0.15$ & $1.95 \pm 0.15$ & $2.06 \pm 0.17$ & 1497.12 & 0.000 & 0.000 & 0.000 & 0.000 \\
\hline
\end{tabular}

${ }^{*} \mathrm{P} 1$ : comparison between 1ry level and 2ry level; ${ }^{*} \mathrm{P} 2$ : comparison between 1ry level and tertiary level; *P3: comparison between 2ry level and tertiary level.

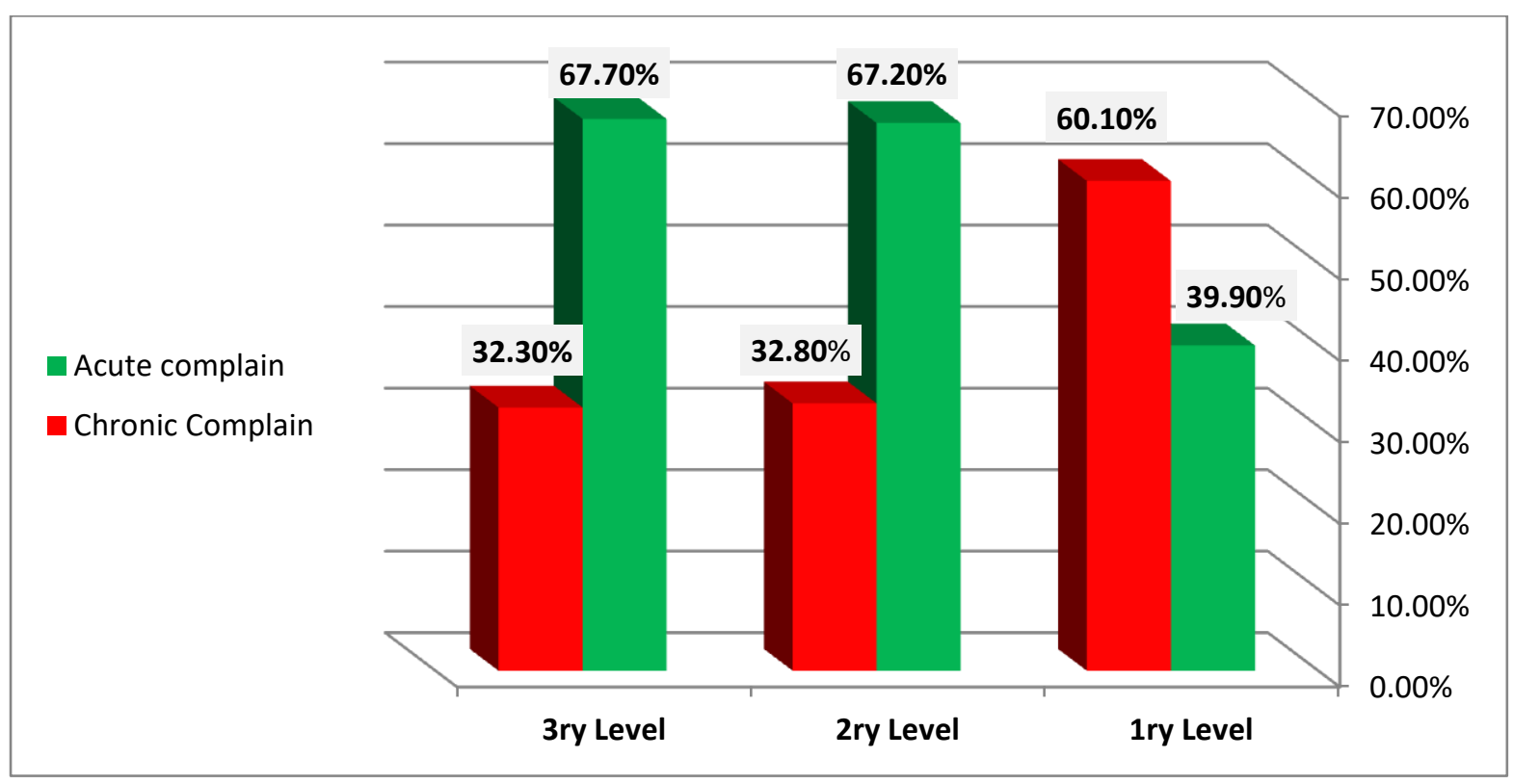

Figure [1]: Frequency distribution of the studied groups according to their complaint and health care levels 


$$
\begin{aligned}
& \text { not satisfied at all } \\
& \text { not satisfied } \\
& \text { acceptable } \\
& \text { satisfied } \\
& \text { very satisfied }
\end{aligned}
$$

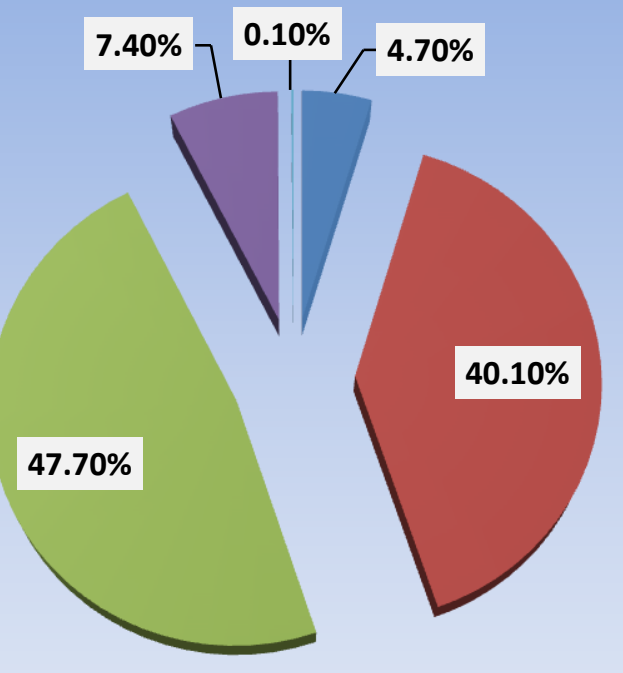

Figure [2]: Level of overall satisfaction among the studied participants about overall received medical services

\section{DISCUSSION}

\section{Socio-demographic characteristics of study participants and healthcare levels}

Patient satisfaction is the real witness to the efficiency of hospital administration. As a hospital provide medical services to all the members of the society, the expectations of clients differ from one person to another because everyone carries a particular set of thoughts, feelings and needs ${ }^{[7]}$.

Our study revealed that the majority of those using health care facilities [77.6\%] were females. This result was expected due to the fact that outpatient hours at the clinics were in the morning and early afternoon, when most of the men were at work. Also, females are frequent bringing their children's to pediatrics clinics than men. This finding is consistent with Gadallah et al. ${ }^{[8]}$ who measured patient satisfaction with primary health care services in two districts in Egypt and reported that [70.6\%] of their sample were females in Belbis district in Sharkia governorate and [60.4\%] of it were females in Abu Korkas district in Minya governorate.

Our results showed that the majority of the studied participants were in the age group 20-40 years [56.3\%] and the mean age of all clients was $33.9 \pm 15.6$ year. These findings are consistent with Bougmiza et al. [9] who measured patient satisfaction about introduced healthcare services at Tunisian hospital showed that majority of clients age was $33.4 \pm 7.5$ years. Our results is against a study conducted by Damghi et al. [10] who measured patients' satisfaction with primary health care services in Qatar and reported that the great majority of the studied population were of old age $55.6 \pm 7.6$ years.

Our results showed that the majority of the studied population was having university education $61.5 \%$ while the minorities have had a basic education $7.5 \%$ and $7.3 \%$ for illiterate. These results may be due to as we considered clients having high institute as a university education and because the primary healthcare center is an urban one. These results are not aligned with a study conducted by Hegazy et al. [11] who measured patient satisfaction about primary health care services at Menoufia Governorate in Egypt, as most patients were illiterate $55.6 \%$, as the study included rural primary healthcare centers.

Our results showed that the majority of clients were not working $66.8 \%$ as we considered housewives females as not working as they have no money making work.

These results are not in accordance with a study conducted in university hospitals in Egypt about patient satisfaction with nursing care by Zahr et al. [12] which revealed that most participants $55 \%$ were having jobs.

This study also revealed that most of studied clients $54.1 \%$ were having not enough income and $39.8 \%$ reported hardly enough income, most of them [82.67\%] with crowding index more than one $[\mathrm{Cl}>1]$, most of them [64.3\%] were frequent attenders and majority [58.3\%] were having acute complaint.

Such findings [not enough income, $\mathrm{Cl}>1$ and frequent attenders] were in agreement with a cross-sectional study by Deriba et al. [13] which revealed that most of the studied population [82\%] were having sufficient income, most of 
them were of low social class [55\%], most of them were frequent attenders to the health care facilities [81\%].

Regarding the frequency distribution of the studied groups according to their socio demographic characteristics and health care levels, our results revealed that there was statistically significant increase level of health care [tertiary level] when age were between 20 to 40 years old for clients with first visit and acute complaint.

Such findings were in agreement with studies by Goben et al. ${ }^{[14]}$ study indicated that large numbers of patients with minor ailments visited the tertiary hospital leading to overload in comparison with the secondary level hospitals and the study recommended a proper referral system in operation in public hospitals, so that the patient load is proportionally distributed and managed well at the primary, secondary, and tertiary levels.

A recent study by Kim-soon et al. [15] indicated that in Libya, tertiary hospitals face ever-increasing outpatient volumes that lead to physicians to be asked to work long hours increasing risk factor for inappropriate prescribing.

A cross-sectional descriptive study by Galal and AlGamal ${ }^{[16]}$ indicated that families bypass often public primary health care services and overuse outpatient clinics in public hospitals in Egypt.

In explanation of the reasons that rural patients are bypassing the primary health care and seeking tertiary hospitals, a previous study by Louis ${ }^{[17]}$ indicated that many factors influence the service-seeking behavior of rural patients bypassing the primary health care that include their perceptions of the quality of primary health care services, the attitudes of health care workers, opening hours of clinics, community participation, and drug availability as well as the quality of the infrastructures'.

\section{Satisfaction score of participants in all domains of satisfaction}

Regarding the level of satisfaction of all studied population with different satisfaction domains, our results indicated that the most satisfaction was about accessibility of health care service [58.5\%] and the less satisfaction was about nurse performance [100\%]. These results could be interpreted as the research settings were all governmental health services that makes the low cost of admission ticket, the low cost of public transportation and the short distance between residence and health care facilities.

Also these results concerning nurse's performance could be explained by lack of regular professional training programs at health organizations about quality of health care and the shortage in nursing staff in Egypt.

Regarding the mean satisfaction score in the studied groups in relation to domains of satisfaction, our results indicated that mean satisfaction score was statistically significant higher among clients attending primary level regarding accessibility, reception service, environment of unit, doctor performance, nurse performance, pharmacy services, patient rights and overall satisfaction. On the other hand mean satisfaction score was statistically significant higher among clients attending tertiary level in comparison to secondary and primary level regarding effectiveness of health care.

Such findings were not in agreement with a cross section study conducted to assess patient satisfaction in outpatient healthcare services at secondary level vs. tertiary level by Stefanovska et al. [18]. The study included 646 clients from outpatient healthcare services at the secondary and tertiary level during the last two months. Clients were significantly more satisfied in tertiary than in secondary outpatient healthcare services in almost all aspects of assessment related to general settings, physician performance and nurse performance.

A cross sectional study conducted by Saini et al. [19] to compare the level of patient satisfaction in the secondary and tertiary outpatient clinics indicated that the overall level of satisfaction was significantly higher in the secondary outpatient clinic and more people were willing to visit it again rather than the tertiary clinic, these results were against our study results in which mean satisfaction score in secondary level group $1.95 \pm 0.15$ was lower than it in tertiary level group 2.06 \pm 0.17 .

\section{CONCLUSION}

The majority $79.8 \%$ of participants in our study were not satisfied with overall services in the study sites. The only domains passed $50 \%$ satisfaction score among the whole participants were the accessibility [75.2\%] and effectiveness [66.8\%] domains. Although clients [tertiary group] were overall not satisfied with services but they considered it as effective and will repeat their visits and recommend it for relatives. So we recommend:

- Continuous and regular evaluation of patient satisfaction and application of quality control measures should applied at outpatient healthcare facilities.

- Administrators in different healthcare facilities should apply measures to reduce waiting times and to increase work hours and times of work at outpatient clinics.

- Cost of laboratory and radiological investigations in 
healthcare facilities should be in accordance with patient's income.

- Clinic pre-booking services and formal referral system between healthcare services should be established to decrease waiting times at out-patient clinics and decrease the load on physicians at clinics.

\section{Financial and Non-financial Relationships and Activities of Interest}

None

\section{REFERENCES}

1. Morris $B J$, Jahangir $A A$, Sethi MK. Patient satisfaction: an emerging health policy issue. Am Acad Orthop Surg. 2013 Jun;9:29. Available from: https://www.aaos.org/aaosnow/2013/ jun/advocacy /advocacy5/

2. Kuzma J, Solomom J, Masono A, Manari B, Hopping J, Pasum $\mathrm{E}$, Yvia J, Tenge K. Assessment of patients' satisfaction with rural health services. Contemp PNG Studies. 2012 Nov; 17:607. DOI: 10.3316/informit.060503813690251.

3. Camgöz-Akdağ H, Zineldin M. Quality of health care and patient satisfaction: An exploratory investigation of the 5Qs model at Turkey. Clin Govern: An Int J. 2010 Apr 27;15[2]:92101. DOI: $10.1108 / 14777271011035031$.

4. Diab HS. Assessment of patients' satisfaction in Ain Shams University Hospitals. Egypt J Bronchol. 2015 Aug;9[2]:211-20. DOI: 10.4103/1687-8426.158107.

5. Keegan TH, DeRouen MC, Press DJ, Kurian AW, Clarke CA. Occurrence of breast cancer subtypes in adolescent and young adult women. Breast Cancer Res. 2012 Mar 27;14(2):R55. DOI: 10.1186/bcr3156.

6. Gadallah M, Zaki B, Rady M, Anwer W, Sallam I. Patient satisfaction with primary health care services in two districts in Lower and Upper Egypt. East Mediterr Health J. 2003 May;9(3):422-30. PMID: 15751936.

7. Cooke M, Irby DM, O'Brien BC. Educating Physicians: A Call for Reform of Medical School and Residency. Washington: The Carnegie Foundation for the Advancement of Teaching 2010. 304.

8. Gadallah M, Zaki B, Rady M, Anwer W, Sallam I. Patient satisfaction with primary health care services in two districts in Lower and Upper Egypt. East Mediterr Health J. 2003 May;9[3]:422-30. PMID: 15751936.

9. Bougmiza I, Ghardallou ME, Zedini C, Lahouimel H, Nabli-Ajmi $\mathrm{T}$, Gataa R, et al. Evaluation de la satisfaction des patientes hospitalisées au service de gynécologie obstétrique de Sousse, Tunisie [Evaluation of the satisfaction of hospitalized patients in a gynecology obstetric department in Sousse,
Tunisia]. Pan Afr Med J. 2011;8:44. French. DOl: 10.4314/pamj.v8i1.71161

10. Damghi N, Belayachi J, Armel B, Zekraoui A, Madani N, Abidi $\mathrm{K}$, et al. Patient satisfaction in a Moroccan emergency department. Int Arch Med. 2013 May 4;6:20. DOl: 10.1186/1755-7682-6-20.

11. Hegazy NN, M Farahat T, A Al Shorbagy E. Socioeconomic Determinants Affecting Compliance to therapy in Patients with Congenital Hypothyroidism in Sharkia Governorate. The Egypt Fam Med J. 2017;1[1]:1-11. DOI: 10.21608/EFMJ.2017.65544.

12. Zahr LK, William SG, el-Hadad A. Patient satisfaction with nursing care in Alexandria, Egypt. Int J Nurs Stud. 1991;28[4]:337-42. DOI: 10.1016/0020-7489[91]90060-g.

13. Deriba BS, Geleta TA, Beyane RS, Mohammed A, Tesema M, Jemal K. Patient Satisfaction and Associated Factors During COVID-19 Pandemic in North Shoa Health Care Facilities. Patient Prefer Adherence. 2020 Oct 13;14:1923-1934. DOI: 10.2147/PPA.S276254.

14. Goben KW, Abegaz ES, Abdi ST. Patient satisfaction and associated factors among psychiatry outpatients of St Paulo's Hospital, Ethiopia. Gen Psychiatr. 2020 Jan 22;33[1]:e100120. DOI: 10.1136/gpsych-2019-100120.

15. Kim-Soon N, Abdulmaged Al, Mostafa SA, Mohammed MA, Musbah FA, Ali RR, Geman O. A framework for analyzing the relationships between cancer patient satisfaction, nurse care, patient attitude, and nurse attitude in healthcare systems. $J$ Ambient Intell Human Comput. 2021 Jan 15:1-8. DOI: 10.1007/s12652-020-02888-x

16. Galal SB, Al-Gamal N. Health problems and the health care provider choices: a comparative study of urban and rural households in Egypt. J Epidemiol Glob Health. 2014 Jun;4[2]:141-9. DOI: 10.1016/j.jegh.2013.12.002.

17. Louis CD. Negotiating change: Approaches to and the distributional implications of social welfare and economic reform. Stanford University; 2011. Available from: https://www.proquest.com/openview/23e71c091ec7e245d224e b2078c2153a/1?pq-origsite=gscholar\&cbl=44156.

18. Stefanovska VV, Petkovska MS. Patient satisfaction in outpatient healthcare services at secondary level vs. tertiary level. Srp Arh Celok Lek. 2014 Sep-Oct;142[9-10]:579-85. DOI: 10.2298/sarh1410579v.

19. Saini NK, Singh S, Parasuraman G, Rajoura O. Comparative assessment of satisfaction among outpatient department patients visiting secondary and tertiary level government hospitals of a district in delhi. Indian J Community Med. 2013 Apr;38[2]:114-7. DOI: 10.4103/0970-0218.112449. 


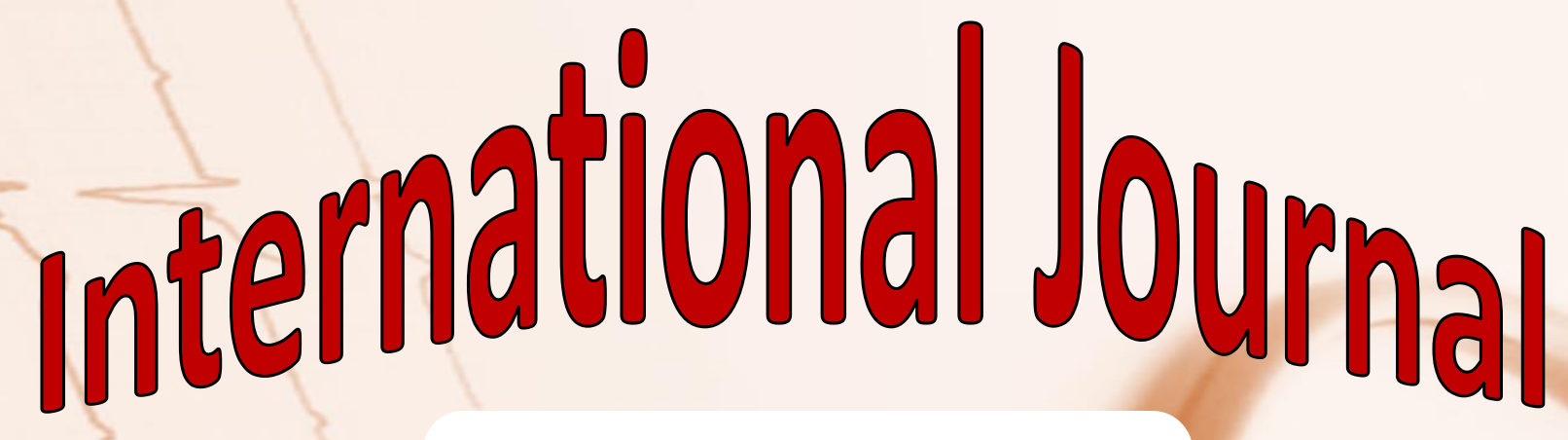

https://ijma.journals.ekb.eg/ Print ISSN: 2636-4174 Online ISSN: 2682-3780

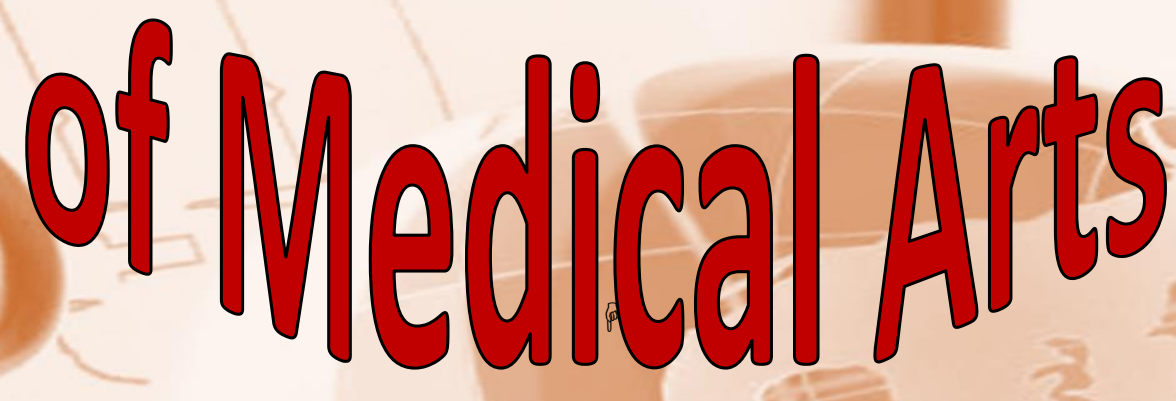

